\title{
ARGUING FOR PhD COURSEWORK
}

\author{
Dr. Mike Metcalfe, \\ Information Systems Doctoral School, \\ University of South Australia (City West), Adelaide, SA 5000 \\ Dr. Margaret Kiley, \\ Advisory Centre for University Education, \\ Adelaide University, South Australia 5005 \\ Correspondence to Mike Metcalfe, tel: 088302 0238, mike.metcalfe@unisa.edu.au
}

\begin{abstract}
The lone-scholar reputation of the traditional UK style $\mathrm{PhD}$ program is the result or a misunderstanding by some course designers. Getting a PhD is as much about making friends, forming a collegiate group, as it is about writing a book. The loneliness should be about being an independent thinker, not to being physically lonely. An increasing number of researchers are now reasserting Aristotle's calls for informed public argument to advance inquiry. Research is an argumentative process, requiring claims and a universal audience of independent thinkers to constructively question those claims. This paper argues for the establishment of semi-structured programs for $\mathrm{PhD}$ students, but importantly, one that undergrirds any program with an appreciation that research is an argumentative process, trying to develop knowledgeable audiences, and thus a social activity.
\end{abstract}

\section{INTRODUCTION}

Most readers will be aware of the British style $\mathrm{PhD}$ program, well characterised by Phillips and Pugh's [1987] phrase "the lone scholar," with students having little regular contact with either a supervisor or other students. Typically this approach has been adopted by Australian Universities. In contrast, the typical doctoral programs in the US (with Minnesota, Indiana and George State excepted) includes a large coursework component where a range of staff and students interact in seminars. The failure of the "Ione-gentleman" approach to produce well trained, enthusiastic, researchers within the allocated three years has attract criticism, yet there is a reluctance to move to the full US approach. A compromise, involving some formal schooling, ( a semi-structured program) but still requiring a large thesis is being considered by an increasing number of Universities in Australasia.

\section{THE ARGUMENT}

This paper will argue for the establishment of a semi-structured program within IS Doctoral schools, but importantly, one with a significant social agenda based on an understanding of the central role of argument in research. Discussion on what subject material (topics) should be included in the program is not of issue here but rather the philosophy undergirding the semi-structured program. For topics, individual school will need to look to their expertise. Typically, though it is assumed to be a first year of optional, flexible, seminars designed to provide $\mathrm{PhD}$ students with research skills, writing skills and/or literature criticism skills culminating in a fairly detailed research proposal. The undergirding philosophy should be aimed at providing students with a perception of research being a local and international collegiate opportunity, derived from understanding that research is a social activity organised around argument for constructive dialectic discourse, not a lonely quest. First though, is there a problem?

\section{SOME BACKGROUND}

The history of PhD's described by Noble [1994] points out that the first doctoral degree was conferred in Paris circa 1150. It was very much based on the idea of providing more teaching to academics to enable them to become teachers or lecturers. It would have involved a "class" activity. The Minister for Education in Berlin, circa 1810 started the first doctoral degree as a schooling for researchers, but it was still very much a group taught degree. These European taught degrees spread to the US by the mid 19th Century. In Britain the first doctoral degrees were nearly 100 years later, post First World War; at Oxford in 1918 and Cambridge in 1919. Unlike the European or US degree the English postgraduate research degree was modeled on the Oxbridge tutoring philosophy used in undergraduate degrees which allowed students a great deal of freedom ${ }^{1}$. It did not expect to dictate to unruly lone gentlemen how or when they had to study, provided they eventually produced a credible piece of written-up research. As these institutions would have assumed that they were very much the centre of the universe, issues of developing a teaching style that encouraged collegiate research would not have been explicitly considered. It seems unfortunate that both types of $\mathrm{PhD}$ used the same label given their very different process.

\footnotetext{
'As an aside it is interesting to reflect on a similar difference in attitudes towards students, stemming from the same period, between the codes for "English" rugby and American Grid-iron. The latter is really a "chess game" played between the two coaches, characterised by the coach's power to stop the game every few minutes to issue instructions. In the English game the coach gives broad tactic advice at the beginning and is then not allowed to "interfere" with the flow of the of the game. The players are treated as "lone scholars."
} 
The purpose, then of the US style $\mathrm{PhD}$ is to train lecturers, future supervisors and researchers, an extension of the undergraduate program. On the other hand, the purpose of the lone-scholar UK style PhD seems mainly to be to offer appreciation or recognition for good research. Both expect a thesis, which in the US maybe thought of as one, maybe two, publishable articles plus a large literature review. The UK-type thesis was expected to produce at least two publishable articles, maybe even be a database for a life's work. However there must be similarities. Administrators of both $\mathrm{PhD}$ programs would most likely say they also hope their graduates are, able and keen to undertake a wide range of further research, well networked, well aware of other research, persons able to initiate with the skills and will to design, and able to complete and effectively communicate a research program. Despite these potential similarities the different philosophies has led to very different experiences, and types of stress.

The US notion of a cohort of doctoral students following a shared and closely monitored framework of research development runs contrary to the individualistic ethos of the lone-gentleman emerging as a "lone-thinker." The idea of teaching students in fully structured programs would be considered to be likely to inhibit both their broader learning, their development, and the encouragement of independent thought. Most UK-type academics would argue that there is something seriously wrong with a doctoral program that is not based on the concept of students having to prove themselves, independently, in the research arena. Indeed UK students have failed if the external examiners feel their work has not been sufficiently independent of even their supervisors thinking.

The culture of individualism within UK trained academia is such that postgraduate students are expected to make their own way in the research world, albeit under the wing of a sole supervisor who will occasionally point them in an appropriate direction. For their part, doctoral students are expected to evaluate and select research areas by themselves, and to produce proposals and plans for research. Thus, the emergent approach emphasises individualism and self-reliance, thereby seeking to develop students confidence in their own abilities.

Students are given "enough rope to hang themselves," and many do. Of course there will be mistakes, learning comes from mistakes. Some research is misconceived, and students sometimes only recognise this after considerable effort has been expended. It is argued, however, that such realisations, together with the resulting reappraisal of the research plan, encourage some considerable depth of independent thought. They facilitate an appreciation of the importance of having clear research objectives, and help to develop the student's understanding of the subject matter, fostering the creativity, flair, and strength of character that is vital for good inquiry.

It is only excusable to do this if students clearly understand the process of research. This includes that research is an argumentative process [Metcalfe, 1995] which requires constant interactions with others, else, the research cannot be effective.

\section{THE PROBLEM}

Evidence that the old lone-gentleman approach may need some revision is provided by completion rates as low as $30 \%$ in some areas reported by DEETYA, the British research councils and by studies by Christopherson et al [n.d.] who report a study conducted across a range of UK universities which indicated that over $50 \%$ of all PhD students took longer than 3 years to complete. They suggest that this rate is lower when students had some kind of framework consisting of regular meetings, formal training and discussion on the literature. They go on to suggest that at the end of one year of this type of semi-structured program the students and supervisors were in a better position to judge whether the student should continue to the thesis stage. In the Australasian and Scottish system, where potential PhD students normally take an extra "honours" year (see later), this can also act as a very effective filter, while allowing the student an interim qualification. Put another way, Christopherson et al concur with Philips and Pugh's finding that student should not proceed to project work (ie a $\mathrm{PhD}$ thesis) without the necessary project management skills, and a collegiate base.

Baddeley [1979] and Wood-Harper et al [1993] also point out that there has been criticism of the lone-scholar doctoral program. They emphasise the "social problems" such as time wasted by students making changes in research direction, students feeling isolated due to access to insufficient peer networks, vulnerability to the personality, leadership style and standing of their supervisor, inapplicability of research findings (lack of general relevance), and a general lack of appreciation of a range of research skills, leading to low completion rates.

That a semi-structued program may be useful has also been confirmed by asking students. Kiley [1996] interviewed 32, including overseas, South Australian students, and found $38 \%$ said they would have liked a group coursework component in their $\mathrm{PhD}$. The exact form of the group work needed to be spelt out before other respondents would commit themselves to the idea. This result needs to be read remembering that anything that extends a PhD for overseas and fee paying students is an added expense.

A student in Kiley's study is quoted as saying the leap from undergraduate to the Honours year is enormous but the leap from "Honours" to PhD nothing. The Australiasian honours year has evolved from the "Scottish" system. It requires an extra year taken after graduation to allow excellent students to be further trained in research methods, further exposed to the research journal publications and undertake a small "trial" dissertation. It can either be used as "pre-training" for a $\mathrm{PhD}$ or simply used to make the student more attractive for employment. It is a similar program to what will later be suggested for a "semi-structured program" in the Doctoral school. Clearly the name "honours" is of no use to UK universities as they offer an honours title to students who get good grades in a three year undergraduate program. However, the impact of this extra "structured" year after undergraduate study, but 
prior to the $\mathrm{PhD}$, means that students who have successfully completed the study program were considered by staff to be desirable PhD candidates as they knew the Department, its research ethos, the collegiality, and thus has inducted students into a collegiate group of like-researchers, ready for the PhD study.

Not only do potential PhD students ask for a semi-structured program, but so do employers. Clarke [1996] found that many PhDs did not make good employees as they were over-specialised, with little skill outside those required for their own $\mathrm{PhD}$, unable to plan and execute experimental work, poor at problem solving, poor at team work, having a lack of appreciation of intellectual property, trademarks, and information-property issues. It is suggested a good structured program would give the students an umbrella of skills, and colleagues, from which they could conduct their $\mathrm{PhD}$, and then later, use for any research required by their future employers.

The UK Economic and Social Research Council [ESRC] [1989], the 1996 Harris report and the 1997 Dearing report, also call for more structure on doctoral programs as support for the students. Harris suggests these support mechanisms should be auditable.

Shannon [1995] argues, "supervision clearly involves research, but ... it also involves teaching, teaching of a special sort." A further argument for having a semi-structured program is that it makes the teaching element in a supervisors work more explicit. $\mathrm{A} \mathrm{PhD} \mathrm{supervisor} \mathrm{has} \mathrm{both} \mathrm{a} \mathrm{teaching} \mathrm{role} \mathrm{and} \mathrm{a} \mathrm{monitoring} \mathrm{role.} \mathrm{Often} \mathrm{the} \mathrm{teaching}$ role is implicit. Lee and Green [1995] agree, saying that the teaching component needs to be taken more seriously. It needs to be more explicit so as to provide a conduit for dialogue between supervisors to discuss the teaching aspect of their work, which can often be considerably enriched by group interaction.

The need for a change to semi-structured program approach to $\mathrm{PhD}$ education is strongly supported by the enormous change in the demographics of students over the last two decades. These changes include that the number of students doing PhDs has increased enormously. Previously, departments may have only had one or two postgraduate students in the past now there may be 10 or 20 . The average age has risen, with more mature aged, experienced, managers returning to study. More students enrol in a PhD's that is very different from their initial studies, or else the material they learnt as undergraduates is no longer at the research edge. This is particularly true in IS. Research methods appropriate to their old studies may no longer be appropriate. There are more international students with a range of different skills depending on the undergraduate course structure from their first degree, more students are coming from industry where the criteria for producing "good" reports can be very different to that required from academia. Furthermore, the motivations for doing a PhD can be very different. Some come "to get a better job," others want it to be a life changing social experience. Some are under a lot of pressure to complete in 3 years, others are willing to take 10 plus years. These differing backgrounds suggest that either care has to be taken in the selection of students or a flexible induction program is required to bring students "up to speed" in whatever deficiency they bring, including forming a collegiate atmosphere. In addition to variation in students background, the same can be said of supervisors. A semi-structured program can be of considerable support to inexperienced supervisors.

A frequent counter to suggestions for a semi-structured program is that students should not be forced to undertake study they don't want. If a student applies for a doctorate with a concise, detailed and well written research proposal then forcing them to go through a semi-structured program may not be appropriate. The proposal would need to exhibit the full range of skills a semi-structured program might have offered. This concern can only be countered by emphasising that any semi-structured program should be flexible, and to a large extent, optional. Importantly, the student also needs to exhibit some appreciation that doing a $\mathrm{PhD}$ should leave him or her, and the department with a group of research associates, as well as a PhD. Having a PhD student that lacks the necessary technical skills can be a considerable draw on the resources of a department, but there is an opportunity cost of having a student that is making no contribution to the development of a collegiate atmosphere in the department's subject area. In Perelman and Olbrecht's [1969] terms the departments needs to develop a universal audience through recognising research to be an argument process.

\section{A SOLUTION}

So how can some of these problems be overcome? One obvious solution is for department Heads to simply have some humanity for the students personal problems, especially overseas students. However, a more academic response is to suggest that the explicit nature of research being an argument be used as the major design driver. This typically will lead to a semi-structured program that, besides technical knowledge, provides a research collegiatcy that satisfies the socialisation needs of students, and the development of the research topic.

How does argument provide the opportunity to develop a collegiate atmosphere? Argument is the noun of arguing or argumentation ${ }^{2}$, the directed construction of convincing evidence [Perelman and Olbrechts Tyteca, 1969; Eemeren et al., 1987], the argument being the one line conclusion that is supported by various evidence. Does'nt

\footnotetext{
${ }^{2}$ Some care has to taken over the word argumentation. Here it is simply being used to mean the process of preparing and presenting an argument; arguing. Some sociologists use the words Argumentation Theory to mean argumentology, the study of past arguments.
} 
this sound like research? A courtroom ${ }^{3}$ analogy can be used. Court protocol has been designed around the open public forum approach also suggested by Aristotle. A court case is a research activity, the courts are also searching for knowledge, indeed, the truth. Evidence is presented to a universal audience (jury) to convince. Society has accepted this research method to take human life, so it would appear to be acceptable, maybe even the best research system on offer.

Evidence presented in order to support an argument can be initially sub-divided into, observation and reasoning (logic). Observation includes participant observation, ethnography, experiments and psychoanalysis, and can be made with any of the human senses, eyes, ears, taste, smell or touch. As anyone who has seen a stick half in water knows, observations are unreliable, discourse is needed to reason why it looks bent. The second type of evidence, reasoning (or logic), uses the mind. In a courtroom example the observation may be forensic evidence, eg. blood on the suspects clothes. The motive would provide the reasoning evidence. So it may be logically concluded that the suspect did the stabbing. So, for example, when presenting research arguing that: system design needs consideration of world views, observation evidence might include what users said about a system and conversations evidence from experienced designers. Reasoning evidence may take the form of explaining what world views are and how they affect perceptions, which in turn affects learning. It is not possible to say what will be sufficient to convince the audience. Hopefully it is sufficient just to say:

In an argument, reasons are oriented in favour of the conclusion... argument is accepted only if the reasons it provides seem plausible, relevant, oriented in favour of the conclusion, and sufficient to support it [Apotheloz et al., 1993].

The important message in this is that research involves argument and argument is a social activity.

Eemeren et al. [1987] also provides a definition of argument:

Argu[ing] is a social, intellectual, verbal [spoken or written] activity serving to justify or refute an opinion [idea, conception, policy], consisting of a constellation of statements and directed towards obtaining the approbation of an audience.

Eemeren et al go on to explain their definition. They start by pointing out that arguments are a social activity because there needs to be two people present. Argument is an intellectual activity, "an activity of reason" where emotion is "subordinate to that of reason." "Argu[ing] requires the use of language." Eemeren et al. contrast this with communication by means of force and associates argument with report writing, logic, mathematics and the use of symbols generally. In research reports, the language usually has to be carefully defined to avoid disputes that turn out to be definitional. So then, the act of arguing aligns itself with the accepted ethos of research.

Eemeren at al. go on.

Argu[ing] always refers to a particular subject concerning which opinions can and do differ... all scientific, scholarly, areas of human knowledge... without any exception whatever, may be the subject of argument.

They provide examples of opinions...

(1) Litmus reacts to acid by changing colour. ...

(2) Amsterdam is the capital of the Netherlands...

They continue, "Argu[ing] is offering, defending against, taking account of, and anticipating criticism." "Argu[ing] consists of a constellation of one or more statements ... "The common feature to both pro-arguments and contra-arguments is that both forms are directed towards testing the opinion." Research, and convincing are the cornerstones of good argument.

... the logical articulation or intellectual cohesion that makes an argument tight comes from thought and not from the mere recitation of the facts or instances [Ziegelmueller and Dause, 1975].

They also put this the other way around:

Research skills stand at the very heart of the inquiry phase of argu[ing]

So, research is arguing which is a social activity. Crosswhite [1995] goes so far as to say that it is one that contributes to world peace by offering an alternative to force.

If students understand that research is a social activity, involving discourse, and their supervisor organises the students semi-structured program around this understanding, doing a $\mathrm{PhD}$ should not be a isolating experience. For

\footnotetext{
"It is better to think of the Royal Commission "courtroom" format, or that used by French and German courts, that is, Judges and lawyers co-operating to find the truth. This contrasts with the English and US approach involving separate lawyers for the defense and the prosecution.
} 
example, any literature review aspects of a semi-structured program may want to do these reviews explicitly using the argument perspective (see appendix 2). If done in a constructive way students can engage the research community in a sociably acceptable way. Moreover, it is a very powerful way to review the literature, especially the management literature that contains more assertions (like this!) than evidence.

The argument strategy is therefore useful at the "planning my PhD activities" level and at the more pragmatic level of layout for the thesis. Under this perspective a thesis is presented as an instrument of the argument, one that presents credible evidence to persuade an informed (hostile) audience partly by anticipating their counter argument. This perspective of research trying to convince the reader leads to a distinctive language for the research proposal, the brief. (See appendix 1). Not only does the argument approach provide a strategy for designing a thesis, it also considerably assists with the problems of writing. Kiley and Mullin's [1998] conference into issues affecting quality in postgraduate education reported that writing skills were a problem. Grammar and spelling can be mechanically corrected, that a piece of writing has no flow, theme, path, direction, purpose, construction; call it what you will, often stems from the writer not appreciating that having an argument gives structure to writing.

Lastly, a short comment about epistemology and bias. This argument approach encourages eclectic empirical methods, aimed at convincing a universal audience, and sidesteps whether discourse is searching for truth or creating it, It assumes the problem being studied, and the audiences requirement to be convinced will select the appropriate sources of knowledge. Moreover, it does not hide researcher bias, unlike the "independent observer" ideology.

\section{CONCLUSION}

This paper offered support for adopting a "semi-structured program" approach to PhD studies in Australia. The traditional $\mathrm{UK}$ approach to $\mathrm{PhD}$ students has produced some very eminent scientists but it has also produced a large number of tired, lonely "also-rans". The differences may be due to a lack of consideration of the philosophy that undergrirds $\mathrm{PhD}$ programs. This paper suggested that this should be that research involves an argumentative process and is therefore a social activity. It is important that both students and those running Doctoral Schools appreciate that the end product is not just a $\mathrm{PhD}$, but a college of competent researchers. All this is best achieved by relistening to Aristotle, more than one world view is required to interpret observation, making research a social activity, advance by well reasoned argument. The loneliness of PhD scholars should refer to their independence of thought as one questioner in a socially active community of scholars offering dialectic questions to each other arguments.

\section{REFERENCES}

Apotheloz D. et al., (1993) The Function of Negation in Argumentation, Journal of Pragmatics, Vol: 19, pp. 2338.

Baddeley, A. (1979) Is the British Ph.D. system obsolete? Bulletin of the British Psychological Society, 32, 129-131.

Christopherson S.D., et al. (n.d.) Research Student and Superviser, Discussion Paper, Swansea, University of Wales, Dept. of Civil Engineering.

Clarke J.A., (1996), Preparation of the PhD for the Real World, Report to the $2^{\text {nd }}$ Seminar of the Council of Deans and Directors, Adelaide University, South Australia.

Crosswhite J. (1996), The Rhetoric of Reason, University of Wisconsin.

Davies, G. (1990) New routes to the Ph.D. The Psychologist: Bulletin of the British Psychological Society, 6, 253-255.

Economic and Social Research Council (1989) Discussion paper on research training in the 1990s. Swindon, UK: ESRC

Economic and Social Research Council (1991) Guidelines on the provision of research trainingfor postgraduate research students in the social sciences. Swindon, UK: ESRC.

Eemeren F.H. at al., (1987), Handbook of Argumentation Theory, Dordrecht:Foris Publications.

Kiley M. (1996), Evaluation of the Structured Program, Report to Adelaide Universty, South Australia.

Kiley M, and Mullins G., (1998) Quality in Postgraduate Research, Adelaide: Conference Proceedings.

Lee L., and Green B., (1995) Postgradutae Studies / Postgradute Pedagogy, The Australian Universities Review, Vol: 38(2), pp:2-4.

Noble K.A., (1994) Changing Doctoral Degrees: An international perspective, England: Open University Press. Perelman Ch. and Olbrecht-Tyteca L., (1969), The New Rhetoric, University of Notre Dame.

Phillips, E. M. \& Pugh, D. S. (1987) How to get a Ph.D. Milton Keynes, UK: Open University Press.

Shannon A., (1995) Research Degree Supervision, The Australian Universities Review, Vol: 38(2), pp.12-15

Walton D. (1998), The New Dialectic, Toronto University Press.

Wood-Harper T. at al. (1993), Designing Research Education in Information Systems,

Included in: Khosrowpour M., Loch, K., (Eds) Global Information technology education: issues and trends. Harrisburg, Pennsilvania, USA 
Ziegelmueller G.W. and Dause C.A., (1975) Argumentation: inquiry and advocacy, New Jersey: Prentice Hall. 


\section{APPENDIX 1}

\section{Research Proposal Format}

In an attempt to demonstrate what the argument approach means in terms of laying out a $\mathrm{PhD}$ proposal, an outline is presented. However, this should be read asking yourself if you have identified the research community or a set of inter-related communities you wish to work with, and who is likely to counter you.

\section{RESEARCH PROPOSAL OUTLINE}

This guide-line for laying out a research proposal is only a suggestion. The headings indicate possible headings are followed by text providing brief explanation. It is important that any evidence be presented as if addressed to the worse opponents of your argument. So, any counter arguments should be fully anticipated. Any empirical work should, therefore, be designed to counter your worse opponents. The argument approach used below assumes the thesis is being written in order to convince these opponents that your argument is correct.

\section{The Argument (Thesis, Theory)}

The argument approach requires that the research question be initially stated as a claim (conclusion). In about one sentence state what you intend to argue. Having an argument, rather than a research question, indicates less arrogance, and some familiarity with the topic. The more surprising your argument the more interesting your thesis.

\section{Definitions:}

Briefly explain any technical keywords used in the argument. This raises the question of, for which audience should the thesis be written. With postgraduate work, the best answer might be, a recent graduate in the discipline of the thesis.

\section{Introduction and Motivation.}

This section is a paragraph explaining why the reader should spend time reading your work. Its aim is to persuade the reader to keep reading. It should also explain why you bothered doing the research.

\section{The Evidence}

The next step might be to list briefly what evidence will be brought to support your argument. This might take the form of other writers' comments, other researchers' findings, sonic logical reasoning on your part and normally some form of empirical study, designed and conducted by you. This part not only outlines your evidence but it also demonstrates your knowledge of the literature. In larger works, this evidence might be summarised as chapter headings.

\section{Previous Arguments}

Here the comments of previous writers can be aired. Counter arguments might be introduced. Care must be taken to avoid "appeals to authority," so the background of any commentators (expert witnesses) used should be explained.

\section{Findings From Previous Empirical Studies}

This section will be characterised by the phrase, "Jones 119851 found that ..." The experimental method of previous studies could be explained here, maybe with the more general findings presented before the more specific findings. The criticisms of any empirical studies should be mentioned. Any counter arguments (rival hypotheses) would also be countered here. A failure to be able to counter some arguments effectively by use of previous writings might guide the choice of empirical study used in the next section.

\section{Own Empirical Evidence}

Your own evidence needs to include empirical evidence as this separates "science from religion." Give details of the methods and expected results. Such evidence might best be designed so as to satisfy your worse critic. A discussion of the criticisms (limitations) in the study design is normally given.

\section{Conclusions and Implications}

As in the summation of the evidence in a trial, the main evidence is reviewed and the conclusion normally that the argument is "proved"

Lastly, the implications of the study might be re-emphasised. These answer the "OK, I agree with you but so-what" questions. To some extent the implications will have been mentioned in the "motivation" section but reiteration and elaboration her can provide a useful conclusion. 
The Title

Present a short title which contains any keywords that would be used in a computer search for this study.

\section{APPENDIX 2}

\section{PREPARING A CRITIQUE OF RESEARCH ARTICLES}

Below are some notes intended to assist your thinking when preparing a critique.

\section{CONTEXT}

In the way of ethnographic studies, what demographic details are known about the paper, the year written, the institutions, motivations for writing, the authors other work, what literature the references are drawn from and how often the paper has been cited (see SSCI). This, and the nature of the paper's argument, may help to establish the author's perspective.

\section{THE ARGUMENT}

- Identify the argument of the paper being critiqued.

- Does the argument have any surprise element? That is, does the study verify or chalienge ?

- Does the author explain all the terminology used in the argument adequately?

- Does she state any limitations in the argument? Does it offer any predictive opportunities?

- Is the argument well integrated, or at least acknowledge the arguments in the existing literature? How so? and,

- Does the author state why the argument is important?

\section{THE EVIDENCE}

- What type of logical evidence is presented? Is it convincing? Outline the steps, and/or

- What type of empirical/observational evidence is presented? Is it convincing, does it use appropriate methods?

\section{CONCLUSIONS / IMPLICATIONS}

- Do you (dis)agree with any stated implications?

- Is it possible to make any type of generalisation s (predictions) from the paper? 